\title{
No evidence for significant association between GABA receptor genes in chromosome 15q11-q13 and autism in a Japanese population
}

\author{
Mamoru Tochigi Chieko Kato $\cdot$ Shinko Koishi $\cdot$ Yuki Kawakubo $\cdot$ Kenji Yamamoto • \\ Hideo Matsumoto · Ohiko Hashimoto · Soo-Yung Kim · Keiichiro Watanabe • \\ Yukiko Kano · Eiji Nanba · Nobumasa Kato $\cdot$ Tsukasa Sasaki
}

Received: 22 August 2007/ Accepted: 26 September 2007/Published online: 24 October 2007

(c) The Japan Society of Human Genetics and Springer 2007

\begin{abstract}
The $\gamma$-aminobutyric acid (GABA) receptor genes GABRB3, GABRA5, and GABRG3 located on chromosome 15q11-q13 have been major candidates for susceptibility genes for autism, a neurodevelopmental disorder with a complex genetic etiology. In this study, we first investigated the association between the GABA receptor genes and autism in a Japanese population by analyzing 11 single nucleotide polymorphisms (SNPs). Intron 3 of $G A B R B 3$ was densely mapped because the previous studies observed the association of the microsatellite 155CA-2 located in the region. We observed no significant difference in allelic frequencies or genotypic
\end{abstract}

M. Tochigi · C. Kato · Y. Kawakubo · S.-Y. Kim ·

K. Watanabe - Y. Kano - N. Kato - T. Sasaki

Department of Neuropsychiatry, Graduate School of Medicine,

University of Tokyo, 7-3-1 Hongo, Bunkyo,

Tokyo 113-8655, Japan

S. Koishi $\cdot$ K. Yamamoto $\cdot$ H. Matsumoto

Department of Psychiatry, Tokai University School of Medicine,

143 Shimokasuya, Isehara, Kanagawa 259-1193, Japan

O. Hashimoto

Department of Medical Technology, Aino University,

4-5-4 Higashi-Ohta, Ibaraki, Osaka 567-0012, Japan

S.-Y. Kim $\cdot$ K. Watanabe $\cdot$ Y. Kano

Department of Child Psychiatry, University of Tokyo Hospital,

7-3-1 Hongo, Bunkyo, Tokyo 113-8655, Japan

E. Nanba

Gene Research Center, Tottori University,

36-1 Nishi-machi, Yonago, Tottori 683-0826, Japan

T. Sasaki $(\bowtie)$

Health Service Center, University of Tokyo,

7-3-1 Hongo, Bunkyo, Tokyo 113-8655, Japan

e-mail: psytokyo@yahoo.co.jp distributions of the 11 SNPs between patients and controls. A permutation test showed no significant global differences in estimated haplotype frequencies between patients and controls. Analysis after confining the subjects to males showed similar results. Thus, this study provides no positive evidence of an association between the GABA receptor genes and autism in a Japanese population. However, in a SNP (rs3212337) located near the microsatellite 155CA-2, a significant deviation from the HardyWeinberg equilibrium was observed in patients $(p=0.029$, corrected for multiple testing). This finding may suggest further studies around the markers for more definitive conclusions.

Keywords Autism - Chromosome 15 - GABA . GABRB3 $\cdot$ SNP

\section{Introduction}

Autism is a developmental disorder characterized by three areas of abnormality: impairment in social interaction, impairment in communication, and restricted and stereotyped pattern of interest or behavior. Impairment in all three areas is observed before age 3 years, and disrupted brain growth of unknown mechanism is implicated in the etiology. Twin and family studies have indicated a robust role of genetic factors in autism development, whereas few susceptibility genes have been elucidated (Freitag 2007). Chromosome $15 q 11-q 13$ has been a focus of genetic studies of autism susceptibility due to the presence of cytogenic abnormalities of this region in autistic patients. The $\gamma$-aminobutyric acid (GABA) receptor genes GABRB3, GABRA5, and GABRG3 located on chromosome 15q11q13 have received considerable attention because a 
decreased GABA receptor density was observed in the hippocampus of autism, and a suppressed GABAergic inhibition has been implicated in autism etiology (Blatt et al. 2001; Hussman 2001).

To our knowledge, 12 studies to date have investigated the genetic association between GABA receptor genes and autism. Two of the studies (Cook et al. 1998; Buxbaum et al. 2002) observed the association of a microsatellite located in intron 3 of GABRB3 (155CA-2), whereas the other four studies did not replicate the association (Salmon et al. 1999; Maestrini et al. 1999; Martin et al. 2000; Curran et al. 2005). Except for 155CA-2, only nominal significant associations were observed with respect to markers located in or around these three GABA receptor genes (Martin et al. 2000; Menold et al. 2001; McCauley et al. 2004; Ashley-Koch et al. 2006). In another three studies, no significant association was observed between the genes and autism (Nurmi et al. 2001; Ma et al. 2005; Kim et al. 2006). Thus, the results were inconclusive, and further investigation may be needed to elucidate the problem. In the study reported here, we investigated the association between GABA receptor genes in chromosome 15q11-q13 and autism in Japanese case-control subjects. To our knowledge, this is the first study to investigate the association in a Japanese population.

\section{Subjects and methods}

In this study, Japanese patients and control subjects around Tokyo, Japan, were recruited: 166 unrelated patients (147 males and 19 females; age $19.9 \pm 9.8$ years, mean \pm SD) with autistic disorder diagnosed by the Diagnostic and Statistical Manual of Mental Disorders, Fourth Edition (DSM-IV) criteria and 412 unrelated healthy volunteers
(136 males and 276 females; age $36.0 \pm 11.5$ years). Patient diagnosis was confirmed by two experienced child psychiatrists independently through semistructured behavior observation and parent interview. At the interview, the Child Behavior Questionnaire Revised (Izutsu et al. 2001) was used to assist the evaluation of autism-specific behaviors and symptoms. After the initial observation and interview, patients were followed up for 6 months to confirm the diagnosis. In order to exclude other genetic syndromes, we performed standard karyotyping and fragile $\mathrm{X}$ testing for the trinucleotide repeat expansion in the FMR-1 gene (Chong et al. 1994). The objective of our study was clearly explained, and written informed consent was obtained from all parents. The consent was also obtained from the patients when they were able to follow the explanation. The study was approved by the Ethical Committee of the Faculty of Medicine, the University of Tokyo.

Genomic DNA was extracted from leukocytes by using the standard phenol-chloroform method. We genotyped 11 single nucleotide polymorphisms (SNPs), as detailed in Table 1. Intron 3 of GABRB3 was densely mapped because the previous studies observed the association of the microsatellite 155CA-2 located in the region (Cook et al. 1998; Buxbaum et al. 2002). The 155CA-2 is located between SNP4 and SNP5 in our study at chromosome position 5170956. All SNPs were analyzed using the ABI PRISM 7900HT Sequence Detection System (Applied Biosystems, CA, USA). The chi-square test was used to compare SNP frequencies between patients and controls. Lewontin's $D^{\prime}$ was used to analyze pairwise linkage disequilibrium (LD) (Lewontin 1964). Haplotype block analysis was conducted with the Gabriel and the Four Gamete methods (Gabriel et al. 2002; Wang et al. 2002). SNP haplotypes and their frequencies were estimated by

Table 1 Allelic frequencies of 11 single nucleotide polymorphisms (SNPs) in the GABR genes

\begin{tabular}{|c|c|c|c|c|c|c|c|}
\hline \multirow[t]{2}{*}{ SNPs } & \multirow[t]{2}{*}{ db SNP ID } & \multirow[t]{2}{*}{ Location } & \multirow{2}{*}{$\begin{array}{l}\text { Alleles } \\
\text { (major/minor) }\end{array}$} & \multicolumn{3}{|c|}{ Minor allele frequency } & \multirow{2}{*}{$\begin{array}{l}\text { Chromosome } \\
\text { position (bp) }\end{array}$} \\
\hline & & & & Autism $^{\mathrm{a}}$ & Control $^{\mathrm{a}}$ & $p$ value & \\
\hline SNP1 & rs11637141 & GABRB3 (3'-UTR) & $\mathrm{C} / \mathrm{T}$ & $0.042(166)$ & $0.055(397)$ & 0.36 & 4954325 \\
\hline SNP2 & rs890317 & GABRB3 (intron 3) & $\mathrm{A} / \mathrm{C}$ & $0.49(164)$ & $0.47(409)$ & 0.60 & 5084462 \\
\hline SNP3 & rs2059574 & GABRB3 (intron 3) & $\mathrm{T} / \mathrm{A}$ & $0.38(166)$ & $0.37(407)$ & 0.95 & 5159328 \\
\hline SNP4 & rs11161335 & GABRB3 (intron 3) & $\mathrm{A} / \mathrm{T}$ & $0.35(160)$ & $0.34(358)$ & 0.74 & 5166381 \\
\hline SNP5 & rs3212337 & GABRB3 (intron 3) & $\mathrm{C} / \mathrm{T}$ & 0.39 (166) & 0.38 (399) & 0.98 & 5173373 \\
\hline SNP6 & rs8179184 & GABRB3 (5' upstream) & $\mathrm{C} / \mathrm{T}$ & $0.38(165)$ & $0.38(407)$ & 0.89 & 5181451 \\
\hline SNP7 & rs140682 & GABRA5 (exon 8) & $\mathrm{C} / \mathrm{T}$ & $0.31(166)$ & $0.35(406)$ & 0.19 & 5343538 \\
\hline SNP8 & rs140685 & GABRA5 (exon 10) & $\mathrm{C} / \mathrm{T}$ & $0.32(166)$ & $0.37(409)$ & 0.14 & 5349640 \\
\hline SNP9 & rs4887536 & GABRG3 (intron 3) & $\mathrm{A} / \mathrm{C}$ & $0.42(166)$ & $0.48(411)$ & 0.073 & 5508122 \\
\hline SNP10 & rs 28564251 & GABRG3 (intron 5) & G/A & $0.40(165)$ & $0.35(348)$ & 0.16 & 5738611 \\
\hline SNP11 & rs 4778109 & GABRG3 (intron 5) & G/A & $0.38(164)$ & $0.36(409)$ & 0.62 & 5884510 \\
\hline
\end{tabular}

${ }^{a}$ Number of genotyped individuals for each SNP is given in parenthesis 
the maximum likelihood method with an expectationmaximization algorithm (Excoffier and Slatkin 1995). Permutation $p$ values were calculated in comparison with haplotype frequencies between patients and controls (Fallin et al. 2001). The SNPAlyze 5.1 standard software (DYNACOM, Japan) was used to conduct LD, haplotype block, and haplotype analyses.

\section{Results}

Table 1 shows allelic frequencies of the 11 SNPs in patients and controls. The distributions of all 11 SNPs follow the Hardy-Weinberg equilibrium in controls. In patients, however, distributions of SNPs 5, 6, and 9 significantly deviated from the Hardy-Weinberg equilibrium ( $p=0.0026,0.018$, and 0.035 , respectively), whereas distributions of the other eight polymorphisms were within the values expected from the Hardy-Weinberg equilibrium. No significant difference was observed in allelic frequencies of the 11 SNPs between the patients and controls. In genotypic distributions, there were significant differences between patients and controls in SNP5 (major homo/hetero/minor homo $=0.32 / 0.59 / 0.09$ vs. $0.38 / 0.47 / 0.15$, respectively, $\chi^{2}=6.65, d f=2, p=0.036$ in codominant model) and SNP9 (0.30/0.57/0.13 vs. 0.26/0.52/0.22, respectively, $\chi^{2}=5.37, d f=1, p=0.021$ in dominant model for major allele). No significant difference was observed in genotypic distributions of the other nine SNPs between patients and controls. Analysis after confining the subjects to males showed no significant difference between patients and controls in allelic frequencies or genotypic distributions of the 11 SNPs (data not shown).

LD strength denoted as $D^{\prime}$ between pairs of the SNPs is shown in Table 2. Two haplotype blocks, SNPs 3-4 and 78 , were suggested by the Gabriel and Four Gamete methods of haplotype-block analysis (Gabriel et al. 2002; Wang et al. 2002). In those analyses, no significant difference was observed in frequencies of any estimated haplotype or in distributions of all estimated haplotypes between patients and controls. Similar results were obtained in LD, haplotype block, and haplotype analyses confining the subjects to males (data not shown).

\section{Discussion}

In this study, we first investigated the association between the three GABA receptor genes, GABRB3, GABRA5, and $G A B R G 3$, and autism in a Japanese population. Nominal significant differences were observed between patients and controls in genotypic distributions of SNPs 5 and 9, although the statistical levels became insignificant after Bonferroni correction. A permutation test showed no significant global difference in estimated haplotype frequencies between patients and controls. Analysis after confining the subjects to males showed similar results. Thus, this study provides no positive evidence of the association between GABA receptor genes and autism in a Japanese population.

Distributions of SNPs 5, 6, and 9 significantly deviated from Hardy-Weinberg equilibrium in patients but not in controls. Statistical levels of deviations in SNPs 6 and 9 became insignificant after Bonferroni correction; however, that in SNP5 was significant (corrected $p=0.029$ ). This could suggest an association of SNP5 with autism, although it might be a chance observation. Also, a possibility of population stratification in the sample may not be completely ruled out. SNP5 is located in intron 3 of GABRB3, $2.4 \mathrm{~kb}$ telomeric from the microsatellite 155CA2, which was suggested to be associated with autism in previous studies (Cook et al. 1998; Buxbaum et al. 2002). It

Table 2 Linkage disequilibrium (LD) strength between single nucleotide polymorphisms (SNP) pairs in patients and controls

\begin{tabular}{llllllllllll}
\hline & SNP1 & SNP2 & SNP3 & SNP4 & SNP5 & SNP6 & SNP7 & SNP8 & SNP9 & SNP10 & SNP11 \\
\hline SNP1 & & 0.49 & 0.51 & 0.22 & 1.00 & 0.51 & 0.38 & 0.47 & 0.04 & 0.43 & 0.09 \\
SNP2 & 0.42 & & 0.05 & 0.08 & 0.13 & 0.05 & 0.14 & 0.15 & 0.08 & 0.04 & 0.02 \\
SNP3 & 0.25 & 0.03 & & 0.89 & 0.88 & 0.92 & 0.09 & 0.05 & 0.14 & 0.15 & 0.10 \\
SNP4 & 0.07 & 0.22 & 0.94 & & 0.93 & 0.96 & 0.05 & 0.07 & 0.12 & 0.29 & 0.17 \\
SNP5 & 0.21 & 0.01 & 0.88 & 0.97 & & 0.96 & 0.13 & 0.14 & 0.12 & 0.07 & 0.06 \\
SNP6 & 0.23 & 0.03 & 0.94 & 0.98 & 0.93 & & 0.07 & 0.08 & 0.14 & 0.13 & 0.07 \\
SNP7 & 0.15 & 0.10 & 0.11 & 0.02 & 0.09 & 0.10 & & 0.97 & 0.30 & 0.19 \\
SNP8 & 0.11 & 0.11 & 0.11 & 0.04 & 0.07 & 0.07 & 0.99 & & 0.24 & 0.16 \\
SNP9 & 0.15 & 0.07 & 0.02 & 0.09 & 0.04 & 0.06 & 0.12 & 0.10 & 0.09 \\
SNP10 & 0.29 & 0.06 & 0.11 & 0.05 & 0.09 & 0.08 & 0.07 & 0.07 & 0.05 & 0.06 \\
SNP11 & 0.14 & 0.03 & 0.13 & 0.01 & 0.08 & 0.09 & 0.03 & 0.06 & 0.06 & 0.01 \\
\hline
\end{tabular}

LD strength is denoted as $D^{\prime} . D^{\prime}$ values for patients are shown in the upper diagonal, and those for controls are shown in the lower diagonal 
may be interesting to further investigate the region around SNP5 or the microsatellite, although no evidence for a significant association was obtained in our study.

Statistical power of this study was $0.77(\alpha=0.05)$ when assuming that the prevalence of autism is $0.21 \%$ in a Japanese population (Honda et al. 1996), genotypic relative risk is 1.8 (dominant model), and marker allele frequency is 0.1 . Thus, our results might have adequate statistical power to detect the effect of the gene, with odds ratios of approximately 1.8 or more, although smaller effects might not have been detected. Caution may be advised for controls because they were not age-matched to patients. However, this likely may not significantly affect the results, considering no major effect of environmental factors in autism (Folstein and Rosen-Sheidley 2001). Imbalance in sex ratio between patients and controls may be overcome by analysis confining subjects to males, considering autism's higher prevalence in males than in females.

In conclusion, no significant association was observed between GABA receptor genes on chromosome 15q11-q13 and autism in the Japanese subjects. However, the significant deviation from Hardy-Weinberg equilibrium in SNP5 might suggest further search for a susceptibility variant around microsatellite 155CA-2.

\section{References}

Ashley-Koch AE, Mei H, Jaworski J, Ma DQ, Ritchie MD, Menold MM, Delong GR, Abramson RK, Wright HH, Hussman JP, Cuccaro ML, Gilbert JR, Martin ER, Pericak-Vance MA (2006) An analysis paradigm for investigating multi-locus effects in complex disease: examination of three GABA receptor subunit genes on $15 \mathrm{q} 11-\mathrm{q} 13$ as risk factors for autistic disorder. Ann Hum Genet 70:281-292

Blatt GJ, Fitzgerald GM, Guptill JT, Booker AB, Kemper TL, Bauman ML (2001) Density and distribution of hippocampal neurotransmitter receptors in autism: an autoradiographic study. J Autism Dev Disord 31:537-543

Buxbaum JD, Silverman JM, Smith CJ, Greenberg DA, Kilifarski M, Reichert J, Cook EH Jr, Fang Y, Song CY, Vitale R (2002) Association between a GABRB3 polymorphism and autism. Mol Psychiatry 7:311-316

Chong SS, Eichler EE, Nelson DL, Hughes MR (1994) Robust amplification and ethidium-visible detection of the fragile $\mathrm{X}$ syndrome CGG repeat using Pfu polymerase. Am J Med Genet 51:522-526

Cook EH Jr, Courchesne RY, Cox NJ, Lord C, Gonen D, Guter SJ, Lincoln A, Nix K, Haas R, Leventhal BL, Courchesne E (1998) Linkage-disequilibrium mapping of autistic disorder, with 15q11-13 markers. Am J Hum Genet 62:1077-1083

Curran S, Roberts S, Thomas S, Veltman M, Browne J, Medda E, Pickles A, Sham P, Bolton PF (2005) An association analysis of microsatellite markers across the Prader-Willi/Angelman critical region on chromosome 15 (q11-13) and autism spectrum disorder. Am J Med Genet 137B:25-28

Excoffier L, Slatkin M (1995) Maximum-likelihood estimation of molecular haplotype frequencies in a diploid population. Mol Biol Evol 12:921-927
Fallin D, Cohen A, Essioux L, Chumakov I, Blumenfeld M, Cohen D, Schork NJ (2001) Genetic analysis of case/control data using estimated haplotype frequencies: application to APOE locus variation and Alzheimer's disease. Genome Res 11:143-151

Folstein SE, Rosen-Sheidley B (2001) Genetics of autism: complex aetiology for a heterogeneous disorder. Nat Rev Genet 2:943955

Freitag CM (2007) The genetics of autistic disorders and its clinical relevance: a review of the literature. Mol Psychiatry 12:2-22

Gabriel SB, Schaffner SF, Nguyen H, Moore JM, Roy J, Blumenstiel B, Higgins J, DeFelice M, Lochner A, Faggart M, Liu-Cordero SN, Rotimi C, Adeyemo A, Cooper R, Ward R, Lander ES, Daly MJ, Altshuler D (2002) The structure of haplotype blocks in the human genome. Science 296:2225-2229

Honda H, Shimizu Y, Misumi K, Niimi M, Ohashi Y (1996) Cumulative incidence and prevalence of childhood autism in children in Japan. Br J Psychiatry 169:228-235

Hussman JP (2001) Suppressed GABAergic inhibition as a common factor in suspected etiologies of autism. J Autism Dev Disord $31: 247-248$

Izutsu T, Osada H, Tachimori H, Naganuma Y, Kato S, Kurita $\mathrm{H}$ (2001) The usefulness of the child behavior questionnaire revised (CBQ-R) as a supplementary scale for diagnosis of pervasive developmental disorders. Rinsyo-Seishin Igaku 30:525-532 (Japanese)

Kim SA, Kim JH, Park M, Cho IH, Yoo HJ (2006) Association of GABRB3 polymorphisms with autism spectrum disorders in Korean trios. Neuropsychobiology 54:160-165

Lewontin RC (1964) The interaction of selection and linkage. I. General considerations; heterotic models. Genetics 120:849-852

Ma DQ, Whitehead PL, Menold MM, Martin ER, Ashley-Koch AE, Mei H, Ritchie MD, DeLong GR, Abramson RK, Wright HH, Cuccaro ML, Hussman JP, Gilbert JR, Pericak-Vance MA (2005) Identification of significant association and gene-gene interaction of GABA receptor subunit genes in autism. Am J Hum Genet 77:377-388

Maestrini E, Lai C, Marlow A, Matthews N, Wallace S, Bailey A, Cook EH, Weeks DE, Monaco AP, the International Molecular Genetics Study of Autism (IMGSA) Consortium (1999) Serotonin transporter (5-HTT) and $\gamma$-aminobutyric acid receptor subunit $\beta 3$ (GABRB3) gene polymorphisms are not associated with autism in the IMGSA families. Am J Med Genet 88:492-496

Martin ER, Menold MM, Wolpert CM, Bass MP, Donnelly SL, Ravan SA, Zimmerman A, Gilbert JR, Vance JM, Maddox LO, Wright HH, Abramson RK, DeLong GR, Cuccaro ML, Pericak-Vance MA (2000) Analysis of linkage disequilibrium in $\gamma$-aminobutyric acid receptor subunit genes in autistic disorder. Am J Med Genet 96:43-48

McCauley JL, Olson LM, Delahanty R, Amin T, Nurmi EL, Organ EL, Jacobs MM, Folstein SE, Haines JL, Sutcliffe JS (2004) A linkage disequilibrium map of the $1-\mathrm{Mb} 15 \mathrm{q} 12 \mathrm{GABA}_{\mathrm{A}}$ receptor subunit cluster and association to autism. Am J Med Genet 131B:51-59

Menold MM, Shao Y, Wolpert CM, Donnelly SL, Raiford KL, Martin ER, Ravan SA, Abramson RK, Wright HH, Delong GR, Cuccaro ML, Pericak-Vance MA, Gilbert JR (2001) Association analysis of chromosome 15 GABAA receptor subunit genes in autistic disorder. J Neurogenet 15:245-259

Nurmi EL, Bradford Y, Chen YH, Hall J, Arnone B, Gardiner MB, Hutcheson HB, Gilbert JR, Pericak-Vance MA, Copeland-Yates SA, Michaelis RC, Wassink TH, Santangelo SL, Sheffield VC, Piven J, Folstein SE, Haines JL, Sutcliffe JS (2001) Linkage disequilibrium at the Angelman syndrome gene UBE3A in autism families. Genomics 77:105-113

Salmon B, Hallmayer J, Rogers T, Kalaydjieva L, Petersen PB, Nicholas P, Pingree C, McMahon W, Spiker D, Lotspeich L, 
Kraemer H, McCague P, Dimiceli S, Nouri N, Pitts T, Yang J, Hinds D, Myers RM, Risch N (1999) Absence of linkage and linkage disequilibrium to chromosome $15 \mathrm{q} 11-\mathrm{q} 13$ markers in 139 multiplex families with autism. Am J Med Genet 88:551556
Wang N, Akey JM, Zhang K, Chakraborty R, Jin L (2002) Distribution of recombination crossovers and the origin of haplotype blocks: the interplay of population history, recombination, and mutation. Am J Hum Genet 71:1227-1234 